\title{
Student Teachers' Social Capitals And Motivations On Online Help-Seeking
}

\author{
Shih-Hsiung Liu \\ National Changhua University of Education \\ Taiwan
}

\begin{abstract}
Requesting help online is a quick way to obtain information to solve practicum-related problems for student teachers because they often serve a poor mentoring quality. The success in acquiring useful information by online help-seeking depends on subjects who are sought and their relationships with seekers. This study investigated the frequency of online help-seeking from two types of social capitals for student teachers in need of suggestions for practicum-related problems and determined the relationships among the amount of social capitals for, perceived benefits of, and motivations on, online help-seeking. A total of 246 Taiwanese secondary student teachers were invited to complete a survey in December 2015. This study concluded that the student teachers sought helps from bonding social capital more than from bridging social capital (BrSC) when meeting practicum-related problems; however, when they have high frequency of help-seeking from BrSC, they could maintain higher amount of BrSC and perceived higher benefits of help-seeking than those with low frequency. Additionally, the perceived benefits of online help-seeking were associated to the motivations of online help-seeking. If student teachers perceive high benefits of online help-seeking, especially from BrSC, they would be willing to seek help online.
\end{abstract}

Keywords: student teacher, social capital, online help-seeking

\section{INTRODUCTION}

\section{Online help-seeking for student teachers from social capital}

Field-based school experiences equip student teachers with the ability to teach. However, student teachers often underestimate the complexity of teaching and perceive a difference between established teaching actions and actual class situations, resulting in an experience of 'reality shock' (Bertone, Meard, Euzet, Ria \& Durand, 2003; Wang \& Lai, 2004). Accordingly, student teachers often experience task failure and emotional frustration (Rogers, \& Keil, 2007). Theoretically, mentor teachers could provide student teachers with useful information to solve practicum-related problems. An emerging phenomenon is that mentor teachers do neither necessarily have a passion for mentoring (Graham, 2006) and sufficient consulting competence (Rodgers \& Keil, 2007), nor provide an adequate combination of emotional support and task assistance for preservice teachers (Crasborn \& Hennissen, 2010). According to Liu (2014), mentor teachers less provided emotional supports. A lack of professionalization of mentoring results in insufficient mentoring quality (Crasborn, Hennissen, Brouwer, Korthagen, \& Bergen, 2011). The uncomfortable situation forces student teachers to seek help from personal outside their practicum schools. Because of the prevalence of mobile technology (e.g., Tablet, smartphone) with various social media (e.g., Facebook, Line, Twitter), requesting help online is a quick way to obtain information to solve a myriad of problems.

The success in acquiring useful information for problem-solving by online help-seeking depends on subjects who are sought and their relationships with seekers. For the student 
teachers, social network sites like Facebook play a vital role in maintaining relationships with their classmates, close friends as well as family members because they move from geographically bounded networks. The maintained relationships often provide student teachers with a resource of emotional support. However, student teachers fail to obtain the useful information about problem-solving from the emotional supporters. Instead, the information from a knowledgeable people and a knowledge sharing site enable student teachers to cope with challenging problems during practicum. It is therefore important for student teachers to build relationships with knowledgeable people or with knowledge community members, in addition to with intimate approach friends.

Lin (1999) considered the above two social relationships (with intimate approach people and with knowledgeable people) as a concept regarding social capital, belonging to individual level and community level, respectively. Social capital refers broadly to the benefits people receive from social relationships. Morrow (1999) suggested that young people with more social capital are more likely to engage in behaviors that lead to better health, academic success, and emotional development. Similarly, Putnam (2000) proposed two distinctive types of social capitals: bonding social capital (BoSC) and bridging social capital (BrSC). The BoSC, similar to the individual level by Lin, refers to the emotional connections between each other. Additionally, the BrSC, corresponding to the community level by Lin, could provide useful suggestions for tasks or new perspectives but typically less emotional support (Granovetter, 1983). The social capital created by these social networks generates broader identities and generalized reciprocity (Williams, 2006).

Notably, because of online technology prevalence, people not only contact real-life familiar friends by social media, but also interact with friends who have never met in real life, resulting in an increase of social capital. However, the two types of social capitals maybe overlap depending on the extent to which people see themselves as a subject for mutual emotional supports and as a member within a broader community.

When both the knowledge previously obtained from teacher education institutes and the suggestions received from mentor teachers cannot satisfy the needs to solve practicum-related problems for student teachers, online help-seeking is a vital way to sustain engagement in practicum learning for student teachers. A considerable amount of studies investigated student teachers' obstacles in participating field-based school experiences (e.g., Hennissen, Crasborn, Brouwer, Korthagen, \& Bergen, 2011); nevertheless, less research involved student teachers' online help-seeking behaviors from social capital. Moreover, Steinfield, Ellison and Lampe (2008) have identified the convenience of using social media to build social relationships with others and further to build social capital for college students. Studies also evidenced that people using social media with high frequency formed more social capital (Ellison, Steinfield, \& Lampe, 2007; Ji, Hwangbo, Yi, Rau, Fang, \& Ling, 2010; Aubrey \& Rill, 2013). Less studies investigated the frequencies of online help-seeking from both subjects (BoSC and BrSC) for student teachers in need of help. This present study addressed the first research question as follows.

Q1. What are the frequencies of online help-seeking for student teachers in need of help from two types of social capitals, respectively?

\section{Amount of social capital and perceived benefits of online help-seeking}

A report measuring social capital from the World Bank specifies six facets of social capital: groups and networks, trust and solidarity, collective action and cooperation, information and 
communication, social cohesion and inclusion, and empowerment and political action (Grootaert, Narayan, Nyhan, \& Woolcock, 2004). According to the report, Lu, Yang, and Yu (2013) developed six concepts to measure social capital: membership of community, development of trust, collective action/cooperation, inclusion/sociability (conflict), smoothing of communication, and power in decision making. The study by Lu et al. indicated that the former five dimensions were affected by the interactions among learners while the last dimension (power in decision making) was not. The last dimension, referring to an individual psychological sense that one has power to influence a decision-making process or a course of action, depends on decision-making projects. However, a study by Schoenacher (2008/2009) indicated that the action regarding power in decision making is a perception that students have the ability to voice their own opinion comfortably. Reasonably, when students can sufficiently express own opinions, the interactions among learners are still related to their amount of social capital.

Furthermore, the amount of social capital influences on knowledge acquirement (Lee \& Badri, 2007) and positively affects learning outcomes in group project (Lu, et al., 2013). Tsai, Ma, Lin, Chiu and Chen (2014) found that the relationship between members of a social network for knowledge sharing becomes tighter in a strong positive tone than in a gloomy mood. In general, people contacts BrSC for discussing administrative matters, while people interacts with BoSC for emotional exchange. The above perspectives imply that the amount of knowledge sharing from BrSC is more than from BoSC. Accordingly, student teachers may acquire more useful information for problem-solving from BrSC than BoSC.

Even though previous studies evidenced that people using social media with high frequency formed more social capital (Ellison, et al., 2007; Ji, et al., 2010; Aubrey \& Rill, 2013), less studies identified the perceived benefits of online help-seeking on the both types of social capitals. More importantly, it is still unclear whether more interactions with social capital lead to higher effectiveness of online help-seeking. Therefore, investigating the frequencies of online help-seeking from the both subjects (bonding and bridging) and the relationships with the amount of social capital as well as perceived benefits of online help-seeking may contribute the literature regarding the online help-seeking behaviors of student teachers. This present study addressed the second research question as follows.

Q2. What are the differences between various frequencies of online help-seeking from both subjects, respectively, in the amount of social capital as well as in perceived benefits of online help-seeking?

\section{Amount of social capital and motivations on online help-seeking}

A study related to online help-seeking of student teachers by (Dindar \& Akbulut, 2014) indicated that many student teachers use social media not as a tool for online help-seeking but merely as a communication tool because of an anxiety about individual privacy being disclosed. Additionally, Steinfield, et al. (2008) identified that self-esteem was a moderated factor between social media use and BrSC for college students and indicated that the students with lower self-esteem obtained more helps than those students with higher self-esteem for BrSC. On the contrary, Phua and Jin (2011) determined that self-esteem had a stronger impact on BoSC rather than BrSC. However, in a study by Ahmad, Mustafa, and Ullah (2016), self-esteem did not reach a significant effect on BoSC, but on BrSC. In the previous studies, the effects of self-esteem on help-seeking vary. A potential reason highlighted by Lall (2014) was users' 
motivation on social media. Ahmad, et al. also found that motives of using social network sites are positively associated with both BoSC and BrSC.

Newman (1994) indicated that a learner's decision to seek help is filtered through an affective system that includes motivational variables. Pintrich and Schunk (1999) proposed three general types of motivational beliefs including: (a) self-efficacy beliefs (judgments of one's capabilities to do the academic task), (b) task value beliefs (beliefs about the importance of, interest in, and value of the task), and (c) goal orientations (whether the focus is on mastery and learning of the task, extrinsic reasons for doing the task, or relative ability in relation to social comparisons with other students).

Studies have mentioned that self-efficacy is related to help-seeking intentions (Cheong, Pajares, \& Oberman, 2004; Pajares, Cheong, \& Oberman, 2004; Roussel, Elliot, \& Feltman, 2011). Selfefficacy refers to the beliefs and expectations regarding own ability to perform a task required to achieve specific outcomes (Bandura, 1997). Cheng and Tsai (2011) have found positive correlations between online help-seeking behavior and self-efficacy in online learning contexts. Pintrich (2003) indicated that students who believe they have more personal control of their own learning and behavior are more likely to do well. Thus, when student teachers perceive their ability and control their learning, they may initiate online help-seeking behaviors.

Moreover, task value beliefs influence help-seeking intentions. Zusho and Barnett (2011) suggested that the motivational variables of task-value and expectancy for success were considered as predictors of help seeking. The task value is a belief about the utility and importance of a task or subject domain. Briefly, when students perceive utility and importance of an academic course and have high level of expectancy for success, they seek helps when needed.

The goal orientations related to mastery and learning of the task are uncertainly related to the intensions of online help-seeking. A study by Huet, Escribe, Dupeyrat, and Sakdavong (2011) indicated that achievement goals in specific academic courses with well-designed learning tasks was not associated with help-seeking behavior. Similarly, Huet, Motak, and Sakdavong (2016) determined that actual help-seeking behavior did not necessarily associated to achievement goals and further explained that the relationship between achievement goals and help-seeking behaviors might depend on the type of academic tasks. Pintrich and Schunk (2002) indicated that the affective component, a student's emotional reactions (e.g., anxiety) to the task, is an important factor for the student's engagement in a certain activity. Combining with the aforementioned perspective on self-esteem influencing social media use, this study proposes that the affective factors, including self-esteem in online help-seeking and anxiety on task, maybe influence online help-seeking of student teachers.

Motivation components influencing student teachers' online help-seeking behaviors vary. Based on the integration of the perspectives on motivation by Pintrich and Schunk (2002) with the empirical studies regarding help-seeking, the motivational beliefs regarding help-seeking for student teachers were categorized into three types: value beliefs (utility and importance of help-seeking), expectancy beliefs (self-efficacy and personal control of help-seeking), and affective beliefs (self-esteem in help-seeking and anxiety on task).

Previous studies have identified that motives of using social network sites are positively associated with social capital (e.g., Ahmad, et al., 2016). This present study further investigated 
the issue about motivation on online help-seeking from two types of social capitals and addressed the third research question as follows.

Q3. What are the relationships between the motivation on online help-seeking and the amount of both types of social capitals, respectively?

\section{Participants}

\section{METHODOLOGY}

Participants were 246 secondary student teachers in Taiwan, of which 71 (28.9\%) were males and 175 (71.1\%) females. They enrolled in school-based field practicum courses at senior high school $(98,39.8 \%)$, at vocational high school $(54,22.0 \%)$, and at junior high school $(94,38.2 \%)$ between August 2015 and January 2016. The student teachers were invited to complete a survey in October 2015.

\section{Instruments}

In this study, a questionnaire, consisting of three scales, presented with a 5-point Likert scale, where 1 was "strongly disagree" and 5 was "strongly agree," were collected to investigate the perceptions among student teachers regarding online help-seeking from social capital, perceived benefits of online help-seeking, and motivation of online help-seeking during practicum. After formulating the initial items of the three scales, three experts in the field of teacher education were consulted to check the content validity of the instrument. The original items were developed in Chinese, and the latter were translated into English for submission.

\section{Online help-seeking from social capital}

This scale consists of two sub-scales: frequencies of online help-seeking from two types of social capitals and the amount of social capitals. There are four items about the frequencies of online help-seeking from BoSC (family member, classmates, peer interns, and close friends) and one item regarding online help-seeking from BrSC (knowledge community member). The items regarding the amount of social capitals was developed based on the six facets of social capital that were mentioned in the literature of this study (Grootaert, et al., 2004). This study has six items measuring social capital.

\section{Perceived benefits of online help-seeking}

According to literature review, when student teachers seek help from social capital, they may perceive benefits of online help-seeking if satisfying the outcomes. This scale has three items, indicating the perceptions of satisfaction, success, and useful knowledge development.

\section{Motivation of online help-seeking}

The items of motivation of online help-seeking were developed based on the perspectives of literature review in this study, revealing that value beliefs (utility and importance of online help-seeking), expectancy beliefs (self-efficacy and personal control of help-seeking), and affective beliefs (self-esteem in online help-seeking and anxiety on task). There were six items in the motivation of online help-seeking scale.

\section{Validity and reliability of the questionnaire}

The questionnaire was validated by item analysis, item-total score correlations, and principal component factor analysis. The Cronbach coefficients on each scale were calculated. The summary of validity and reliability of the three scales reveals in Table 1. 
Table 1. The summary of validity and reliability of the three scales

\begin{tabular}{|c|c|c|c|c|c|c|c|c|}
\hline & & \multirow{2}{*}{$\begin{array}{l}\text { Item } \\
\text { analysi } \\
\mathrm{s}\end{array}$} & \multirow{2}{*}{$\begin{array}{l}r \\
\text { coeff. }\end{array}$} & \multicolumn{3}{|c|}{ Factor analysis } & \multirow{2}{*}{$\begin{array}{l}\text { loadin } \\
\mathrm{g}\end{array}$} & \multirow{2}{*}{$\begin{array}{l}\text { Cronbac } \\
\text { h } \\
\text { coeff. }\end{array}$} \\
\hline & & & & KMO & Bartlett & $r^{2}(\%)$ & & \\
\hline \multirow{2}{*}{$\begin{array}{l}\text { BoS } \\
\text { C }\end{array}$} & $\begin{array}{l}\text { amoun } \\
t \text { of }\end{array}$ & $>12.30^{*}$ & $>0.80$ & $\begin{array}{l}0.91 \\
0\end{array}$ & $\begin{array}{l}1269.49 \\
*\end{array}$ & $\begin{array}{l}76.64 \\
\%\end{array}$ & $>0.786$ & 0.937 \\
\hline & $\begin{array}{l}\text { benefits } \\
\text { from }\end{array}$ & $>15.18^{*}$ & $\begin{array}{l}>0.85 \\
*\end{array}$ & $\begin{array}{l}0.72 \\
3\end{array}$ & $291.80^{*}$ & $\begin{array}{l}75.58 \\
\%\end{array}$ & $>0.852$ & 0.838 \\
\hline \multirow{2}{*}{$\mathrm{BrSC}$} & $\begin{array}{l}\text { amoun } \\
\text { t of }\end{array}$ & $>15.12^{*}$ & $\begin{array}{l}>0.87 \\
*\end{array}$ & $\begin{array}{l}0.91 \\
3\end{array}$ & 1169.95 & $\begin{array}{l}78.80 \\
\%\end{array}$ & $>0.873$ & 0.946 \\
\hline & $\begin{array}{l}\text { benefit } \\
\text { s from }\end{array}$ & $>14.89^{*}$ & $\begin{array}{l}>0.90 \\
*\end{array}$ & $\begin{array}{l}0.74 \\
9\end{array}$ & $368.62^{*}$ & $\begin{array}{l}82.08 \\
\%\end{array}$ & $>0.901$ & 0.890 \\
\hline \multicolumn{2}{|c|}{$\begin{array}{l}\text { motivation of help- } \\
\text { seeking }\end{array}$} & $>11.69^{*}$ & $\begin{array}{l}>0.76 \\
*\end{array}$ & $\begin{array}{l}0.88 \\
2 \\
\end{array}$ & $907.32^{*}$ & $\begin{array}{l}68.11 \\
\%\end{array}$ & $>0.741$ & 0.905 \\
\hline
\end{tabular}

\section{Homogeneity of data}

A one-way analysis of variance was calculated to determine whether the reports of the preservice teachers on five factors (as follows) exerted dissimilar influences between the four types of practicum schools. The analytical results revealed nonsignificant variations among the amount of BoSC (F value $=0.079, \mathrm{p}=.971>0.05)$, perceived benefits from BoSC ( $\mathrm{F}$ value $=0.126, \mathrm{p}=.945>0.05)$, the amount of $\mathrm{BrSC}(\mathrm{F}$ value $=0.102, \mathrm{p}=.903>0.05)$, perceived benefits from $\mathrm{BrSC}(\mathrm{F}$ value $=0.498, \mathrm{p}=.608>0.05)$, motivation of help-seeking $(\mathrm{F}$ value $=$ $0.458, p=.712>0.05$ ), respectively. The above results eliminated the possibility of practicumschool types affecting any of the factors in this study.

\section{The frequencies of help-seeking from social capitals}

\section{RESULTS AND DISCUSSION}

The analytical results of this study in Table 2 reveal that the student teachers sought more help to classmates than family member as well as close friends within BoSC. Additionally, of which those enrolling in the survey, 30 student teachers did not seek help from BrSC (i.e., knowledge community members). That is, not all student teachers manipulate BrSCs to seek help for solving practicum-related problems. Another analytical result of the study as Table 3 shows that the student teachers sought help with higher frequency from BoSC than BrSC. Approximately $77 \%$ of student teachers sought help from BoSC more than twice in a week, while merely 46\% sought help from BrSC in the same frequency. Notably, even though 216 student teachers reported having sought help from BrSC, 40 of them (18.5\%) contacted knowledge community members merely once or less in a month. The aforementioned finding shows that the student teachers less employed BrSC when meeting practicum-related problems.

Table 2. The summary of online help-seeking from various member of social capital

\begin{tabular}{|c|c|c|c|}
\hline $\begin{array}{l}\begin{array}{l}\text { Type of social } \\
\text { capital }\end{array} \\
\end{array}$ & Subjects for help-seeking & did not & did \\
\hline \multirow{3}{*}{ BoSC } & family members & $112(45.5 \%)$ & $134(54.5 \%)$ \\
\hline & classmates & $34(13.8 \%)$ & $212(86.2 \%)$ \\
\hline & close friends & $118(48.0 \%)$ & $128(52.0 \%)$ \\
\hline $\mathrm{BrSC}$ & $\begin{array}{l}\text { knowledge } \\
\text { members }\end{array}$ & $30(12.2 \%)$ & $216(87.8 \%)$ \\
\hline
\end{tabular}


Table 3. The frequencies of online help-seeking from two types of social capitals

\begin{tabular}{lclllll}
\hline $\begin{array}{l}\text { social } \\
\text { capital }\end{array}$ & Num. & $\begin{array}{l}\text { Once or less } \\
\text { than } \\
\text { /month }\end{array}$ & $\begin{array}{l}\text { Twice- } \\
\text { thrice } \\
\text { /month }\end{array}$ & $\begin{array}{l}\text { Once } \\
\text { /week }\end{array}$ & $\begin{array}{l}\text { Twice- } \\
\text { thrice } \\
\text { /week }\end{array}$ & $\begin{array}{l}\text { Once or more } \\
\text { than one /day }\end{array}$ \\
\hline BoSC & 246 & $7(2.8 \%)$ & $22(8.9 \%)$ & $27(11.0 \%)$ & $70(28.5 \%)$ & $120(48.8 \%)$ \\
BrSC & 216 & $40(18.5 \%)$ & $31(14.4 \%)$ & $45(20.8 \%)$ & $66(30.6 \%)$ & $34(15.7 \%)$ \\
\hline
\end{tabular}

Theoretically, BoSC provides emotional supports while BrSC offers professional suggestions in social networks (Putnam, 2000). The student teachers should seek help online from BrSC rather than from BoSC when they meet practicum-related problems. However, this aforementioned result of this study is opposite to the theoretical perspectives.

According to Dindar and Akbulut (2014), many student teachers used social media not as a tool for help-seeking but merely as a communication tool because of an anxiety about individual privacy being disclosed. The student teachers were anxious about presenting their own shortcomings for non-intimate-approach friends (i.e., BrSC) during help-seeking.

Moreover, 30 of them participating in the survey did not join in any knowledge sharing community. In addition to the mentioned anxiety, the minority of student teachers maybe did not know where have, and how to participate in, professional communities related to fieldbased school experiences. Basically, the student teachers interacted with BoSC for a long time, such as a university classmate relationship for four years, while most of them contact the members of BrSC (i.e., participating in knowledge sharing communities) for a short time because the field-based school experiences is merely a half year. The different time-period of contact maybe result in various frequencies in help-seeking from different of social capital. The above descriptions could indicate why practicum-related the student teachers sought help from BoSC more than BrSC.

\section{The differences between various frequencies of online help-seeking from social capitals}

Table 4 reveals the differences between various frequencies of online help-seeking in the amount of social capitals and perceived benefits of online help-seeking. The analytical result of this study found no difference in the amount of $\operatorname{BoSC}(\mathrm{F}=3.190, \mathrm{p}<.05$, but no significant differences by post hoc) and in the perceived benefits of online help-seeking from BoSC $(\mathrm{F}=1.225, \mathrm{p}>.05)$. That is, the frequency of online help-seeking from BoSC is not related to the amount of BoSC as well as the perceived benefits of online help-seeking from BoSC. However, another analytical results in this study achieved significant differences between various frequencies of online help-seeking in the amount of BrSC and in the perceived benefits of online help-seeking. This study further found that the student teachers with high frequency of online help-seeking from BrSC had higher amount of BrSC than those with low frequency. Similarly, the student teachers with high frequency of online help-seeking from BrSC perceived more benefits of online help-seeking than those with low frequency. The above study findings indicate that when student teachers seek help online from BrSC for problem-solving, they not only maintain BrSC but also perceive benefits of online help-seeking. 
Table 4. The differences between various frequencies of help-seeking from social capitals

\begin{tabular}{|c|c|c|c|c|}
\hline Types of social capital & frequency & $\mathrm{M}$ & SD & Post Hoc \\
\hline \multirow{5}{*}{$\begin{array}{l}\text { amount of BoSC } \\
\mathrm{N}=246\end{array}$} & $\begin{array}{l}\text { Once or less than } \\
\text { one /month }(A)\end{array}$ & 4.26 & 0.59 & \multirow{5}{*}{$\begin{array}{l}F=3.190 \\
p=.014 \\
\text { n.s. }\end{array}$} \\
\hline & $\begin{array}{l}\text { Twice-thrice } \\
\text { /month (B) }\end{array}$ & 4.27 & 0.44 & \\
\hline & Once /week (C) & 4.13 & 0.67 & \\
\hline & $\begin{array}{l}\text { Twice-thrice } \\
\text { /week (D) }\end{array}$ & 4.27 & 0.81 & \\
\hline & $\begin{array}{l}\text { Once or more than } \\
\text { one / day (E) }\end{array}$ & 4.51 & 0.54 & \\
\hline \multirow{5}{*}{$\begin{array}{l}\text { perceived benefits of } \\
\text { online help-seeking from } \\
\text { BoSC } \\
\mathrm{N}=246\end{array}$} & (A) & 4.19 & 0.50 & \multirow{5}{*}{$\begin{array}{l}F=1.225, \\
p=.301\end{array}$} \\
\hline & (B) & 3.95 & 0.47 & \\
\hline & (C) & 3.97 & 0.81 & \\
\hline & (D) & 4.09 & 0.80 & \\
\hline & (E) & 4.21 & 0.60 & \\
\hline \multirow{5}{*}{$\begin{array}{l}\text { amount of BrSC } \\
\mathrm{N}=216\end{array}$} & (A) & 3.47 & 0.86 & \multirow{5}{*}{$\begin{array}{l}F=10.364, \\
p=.000 \\
(E)>(A),(E) \\
>(B) \\
(D)>(A) \\
(C)>(A)\end{array}$} \\
\hline & (B) & 3.82 & 0.55 & \\
\hline & (C) & 4.15 & 0.79 & \\
\hline & (D) & 4.23 & 0.75 & \\
\hline & $(\mathrm{E})$ & 4.41 & 0.53 & \\
\hline \multirow{5}{*}{$\begin{array}{l}\text { perceived benefits of } \\
\text { online help-seeking from } \\
\text { BrSC } \\
N=216\end{array}$} & (A) & 3.72 & 0.71 & \multirow{5}{*}{$\begin{array}{l}F=4.005 \\
p=.004 \\
(\mathrm{E})>(\mathrm{A})\end{array}$} \\
\hline & (B) & 3.78 & 0.60 & \\
\hline & $(\mathrm{C})$ & 3.93 & 0.90 & \\
\hline & (D) & 4.14 & 0.76 & \\
\hline & $(\mathrm{E})$ & 4.24 & 0.54 & \\
\hline
\end{tabular}

The previous studies have evidenced that people with high frequency of interacting with friends by social media could form strong social capitals (Ellison, et al., 2007; Ji, et al., 2010; Aubrey \& Rill, 2013). This present study indicates that interactions with knowledgeable friends not only benefit student teachers in strengthening the amount of BrSC, but also satisfy themselves in help-seeking. As for BoSC, no significant difference in frequency of help-seeking implies that online emotional exchange could not enhance the amount of BoSC.

Even though more online help-seeking from BoSC than from BrSC, the student teachers did not strengthen the relationships with BoSC and perceive the benefits of online help-seeking from BoSC. As a study by Tsai, et al. (2014), indicating that a professional tone benefits the building of the relationship with members of a social network, this present study proposes that student teachers with high frequency of online help-seeking from BrSC obtain useful information for problem-solving and further maintain the close relationships with BrSC. Useful information seems to be a key point in maintaining BrSC. On the other hand, the building of the relationships with BoSC did not origin from the professional tone but an affective perception, resulting in that online help-seeking for problem-solving cannot enhance the relationships with BoSC. The descriptions explain why the student teachers with high frequency of helpseeking from social capitals maintained high amount of BrSC rather than BoSC.

Notably, a contradictory phenomenon is emerging by combining the above results (more benefits of online help-seeking from BrSC than BoSC) with the study finding aforementioned in 
section 3.1 (student teachers contacted the members of BrSC less than the members of BoSC): When student teachers meet practicum-related problems, they should seek help from BrSC rather than BoSC; however, they often contacted BoSC in this study.

The relationships between the motivation on help-seeking and the amount of each social capital According to the above study findings, student teachers should be encouraged to seek help from BrSC; however, they performed online help-seeking less from BrSC than from BoSC. Accordingly, the motivations of help-seeking from two types of social capitals are worthy of investigations.

Table 5 reveals the relationships between the motivations of online help-seeking and the two types of social capitals, respectively. Pearson's correlation technique was utilized to evaluate the quality of the relationship. According to Cohen's recommendation (1988), interpretations of correlation effect size are based on correlation coefficients with absolute values: small effect $(\geq 0.1,<0.3)$, medium effect $(\geq 0.3,<0.5)$, and large effect $(\geq 0.5)$. According to the analytical results of this study, the student teachers' motivation of online help-seeking was a small effect on the relationship with BoSC, while the motivation of online help-seeking has a medium effect on the relationship with BrSC. The study finding indicates that when the student teachers perceive larger amount of social capital as well as more benefits of online help-seeking, they have higher motivations of online help-seeking, especially from BrSC which effect is larger than BoSC.

Table 5. The relationships between the motivations of online help-seeking with the amount of each social capital

\begin{tabular}{lllllll}
\hline & M & SD & (A) & (B) & (C) & (D) \\
\hline amount of BoSC (A) & 4.38 & 0.65 & & & & \\
perceived benefits from BoSC (B) & 4.13 & 0.68 & & & & \\
motivations of online help-seeking (E) 4.16 & 0.61 & $.271^{* *}$ & $.280^{* *}$ & & \\
\hline amount of BrSC (C) & 4.04 & 0.79 & & & & \\
perceived benefits from BrSC (D) & 3.99 & 0.75 & & & & \\
motivations of online help-seeking (E) 4.10 & 0.61 & & & $.446^{* *}$ & $.454^{* *}$ \\
\hline
\end{tabular}

Studies have evidenced that student teachers often experience a 'reality shock' due to an underestimate on the complexity of teaching (Bertone, Meard, Euzet, Ria \& Durand, 2003; Wang \& Lai, 2004). Zusho and Barnett (2011) indicated that when students perceive utility and importance of task, they initiate online help-seeking. This study further found that the perceived benefits of online help-seeking were associated to the motivations of online helpseeking, especially from BrSC. However, surprisingly, the student teachers less sought help from BrSC than from BoSC according to the first findings of this study.

\section{CONCLUSION AND IMPLICATION}

This study investigated the frequency of online help-seeking from two types of social capitals for student teachers in need of suggestions for practicum-related problems and determined the relationships among the amount of social capitals for, perceived benefits of, and motivations on, online help-seeking. This study concluded that the student teachers sought helps from BoSC more than from BrSC when meeting practicum-related problems; however, when they have high frequency of help-seeking from BrSC, they could maintain higher amount of BrSC and perceived higher benefits of help-seeking than those with low frequency. Restated, when 
student teachers meet practicum-related problems, they should contact BrSC rather than BoSC; however, they often contacted BoSC in this study. Additionally, this study also determined that the perceived benefits of online help-seeking were associated to the motivations of online helpseeking. If student teachers perceive high benefits of online help-seeking, especially from BrSC, they would be willing to seek help online.

According to the conclusions of this study, student teachers should be encouraged to interact with knowledgeable friends as well as knowledge community member and further obtain useful information for solving practicum-related problems. Moreover, this study infers that useful information from social capital seems to be a key point in maintaining social capital. Future studies could deeply explore the content of interactions with the members of knowledge community for student teachers and further understand which information is required. Additionally, the factor regarding that the student teachers sought help from BoSC more than BrSC when they were in need of help during practicum is also worthy of investigation.

The student teachers of this study enrolled in field-based experiences merely for a half year; that is, they maybe maintain BrSC for a half year. This study cannot identify the time period of when BoSC was built. Accordingly, this study has one limitation: the effects of frequencies of online help-seeking from different of social capitals on the amount of social capitals may differ for student teachers because of the different of time period in building two types of social capitals.

\section{References}

1. Ahmad, S., Mustafa, M., \& Ullah, A. (2016). Association of demographics, motives and intensity of using Social Networking Sites with the formation of bonding and bridging social capital in Pakistan. Computers in Human Behavior, 57, 107-114.

2. Aubrey, J. S., \& Rill, L. (2013). Investigating relations between Facebook use and social capital among college undergraduates. Communication Quarterly, 61(4), 479-496.

3. Bandura, A. (1997). Self-efficacy: The exercise of control. New York: Freeman.

4. Bertone, S., Meard, J. Euzet, J. Ria, L. and Durand, M. (2003), Intrapsychic conflict experienced by a preservice teacher during classroom interactions: a case study in physical education. Teaching and Teacher Education, 19, 113-125.

5. Cheng, K.-H., \&Tsai, C.-C. (2011). An investigation of Taiwan University students' perceptions of online academic help seeking and their web-based learning self-efficacy. Internet and Higher Education, 14, 150157.

6. Cheong, Y. F., Pajares, F., \& Oberman, P. (2004). Motivation and academic help-seeking in high school computer science. Computer Science Education, 14, 3-19.

7. Cohen, J. (1988). Statistical power analysis for the behavioral sciences (2nd ed.). Lawrence Erlbaum Associates.

8. Cohen, L., Manion, L., \& Morrison, K. (2007). Research Methods in Education. London: Routledge.

9. Crasborn, F., \& Hennissen, P. (2010). The skilled mentor: Mentor teachers' use and acquisition of supervisory skills. Eindhoven: Eindhoven School of Education.

10. Crasborn, F., Hennissen, P., Brouwer, N., Korthagen, F., \& Bergen, T. (2011). Exploring a two-dimensional model of mentor teacher roles in mentoring dialogues. Teaching and Teacher Education, 27, 320-331.

11. Dindar, M., \& Akbulut, Y. (2014). Why do pre-service teachers quit Facebook? An investigation on 'quitters forever' and 'quitters for a while'. Computers in Human Behavior, 39, 170-176. 
12. Ellison, N. B., Steinfield, C., \& Lampe, C. (2007). The benefits of Facebook "friends": Social capital and college students' use of online social network sites. Journal of Computer-Mediated Communication, 12(4), 1143-1168.

13. Graham, B. (2006). Conditions for successful field experiences: Perceptions of cooperating teachers. Teaching and Teacher Education, 22(8), 1118-1129.

14. Granovetter, M. (1983). The strength of weak ties: A network theory revisited. Sociological Theory, 1, 201-233.

15. Grootaert, C., Narayan, D., Nyhan J. V., \& Woolcock, M. (2004). Measuring social capital- An integrated questionnaire, World Bank working paper No. 18.

16. Hennissen, P., Crasborn, F., Brouwer, N., Korthagen, F., \& Bergen, T. (2011). Clarifying pre-service teacher perceptions of mentor teachers' developing use of mentoring skills. Teaching and Teacher Education, 27(6), 1049-1058.

17. Hodkinson, H., \& Hodkinson, P. (2005). Improving schoolteachers' workplace learning. Research Papers in Education, 20, 109-131.

18. Huet, N., Escribe, C., Dupeyrat, C., \& Sakdavong, J. C. (2011). Achievement goals and perceptions of on line help on the actual use of help in interactive learning environment. Computers in Human Behavior, 27, 413-420.

19. Huet, N., Motak, L., \& Sakdavong, J. C. (2016). Motivation to seek help and help efficiency in students who failed in an initial task. Computers in Human Behavior, 63, 584-593.

20. Ji, Y. G., Hwangbo, H., Yi, J. S., Rau, P. P., Fang, X., \& Ling, C. (2010). The influence of cultural differences on the use of social network services and the formation of social capital. International Journal of HumanComputer Interaction, 26(11/12), 1100-1121.

21. Lee L. T.-S., \& Badri, M. S. (2007). The effects of entrepreneurial orientation and knowledge management capability on organizational effectiveness in Taiwan: The moderating role of social capital. International Journal of Management, 24(3), 549-573.

22. Lin, N. (1999). Building a network theory of social capital. Connections, 22, 28-51.

23. Liu, S.-H. (2014). Excellent mentor teachers'skills in mentoring for pre-service teachers. International Journal of Education, 6(3), 29-42.

24. Lu, J., Yang, J., \& Yu, C. (2013). Is social capital effective for online learning? Information \& Management, 50, 507-522.

25. Morrow, V. (1999). Conceptualizing social capital in relation to the well-being of children and young people: a critical review. Sociological Review, 47, 744-765.

26. Newman, R. S. (1994). Adaptive help seeking: A strategy of self-regulated learning. In D. H. Schunk \& B. J. Zimmerman (Eds.), Self-regulation of learning and performance: Issues and educational applications (pp. 283-301). Hillsdale: Erlbaum.

27. Pajares, F., Cheong, Y. F., \& Oberman, P. (2004). Psychometric analysis of computer science help-seeking scales. Educational and Psychological Measurement, 64, 496-513.

28. Phua, J., \& Jin, S. A. A. (2011). 'Finding a home away from home': the use of social networking sites by Asia-Pacific students in the United States for bridging and bonding social capital. Asian Journal of Communication, 21(5), 504-519.

29. Pintrich, P. R. (1999). The role of motivation in promoting and sustaining self-regulated learning. International Journal of Educational Research, 31, 459-470.

30. Pintrich, P. R. (2003). A motivational science perspective on the role of student motivation in learning and teaching contexts. Journal of Educational Psychology, 95(4), 667-686.

31. Pintrich, P. R., \& Schunk, D. H. (2002). Motivation in education: Theory research, and applications (2nd ed.). Englewood Cliffs. NJ: Prentice Hall Merrill.

32. Putnam, R. D. (2000). Bowling alone: The collapse and revival of American community. New York: Simon \& Schuster. 
33. Rodgers, A. \& Keil, V. (2007). Restructuring a traditional student teacher supervision model: Fostering enhanced professional development and mentoring within a professional development school context. Teaching and Teacher Education, 23(1), 63-80.

34. Roussel, P., Elliot, A. J., \& Feltman, R. (2011). .The influence of achievement goals and social goals on helpseeking from peers in an academic context. Learning and Instruction, 21, 394-402.

35. Schoenacher, S. R. (2008/2009). Building social capital through online class discussions: a little freedom goes a long way. Journal of Educational Technology Systems, 37(3), 291-304.

36. Steinfield, C., Ellison, N. and Lampe, C. (2008). Social capital, self-esteem, and use of online social network sites: A longitudinal analysis. Journal of Applied Developmental Psychology, 29 (6), 434-445.

37. Strike, K. A., \& Posner, G. J. (1992). A revisionist theory of conceptual change. In R. A. Dulsch \& R. J. Hamilton (Eds.), Philosophy of science, cognitive psychology, and educational theory and practice (pp. 147-176). New York: State University of New York.

38. Tsai, Y. -H., Ma, H. -Chun., Lin, C. -P., Chiu, C. -K., \& Chen, S. -C. (2014). Group social capital in virtual teaming contexts: A moderating role of positive affective tone in knowledge sharing. Technological Forecasting \& Social Change, 86, 13-20.

39. Wang, S. Y., \& Lai, K. J. (2004). Conceptual analysis of educational practicum: in the case of the practicum system and reform in Taiwan. Journal of National Institute for Compilation and Translation, 32(1), 48-59.

40. Williams, D. (2006). On and off the 'net: Scales for social capital in an online era. Journal of ComputerMediated Communication, 11(2), 593-628.

41. Zusho, A., \& Barnett, P. A. (2011). Personal and contextual determinants of ethnically diverse female high school students' patterns of academic help-seeking and help avoidance in English and mathematics. Contemporary Educational Psychology, 36(2), 152-164. 